\title{
Antimicrobial use, incidence, etiology and resistance patterns in bacteria causing ventilator-associated pneumonia in a clinical-surgical intensive care unit
}

\author{
Michel Rodrigues Moreira ${ }^{[1]}$, Munick Paula Guimarães ${ }^{[1]}$, \\ Aurélia Aparecida de Araújo Rodrigues ${ }^{[2]}$ and Paulo Pinto Gontijo Filho ${ }^{[1]}$
}

[1]. Laboratório de Microbiologia, Instituto de Ciências Biomédicas, Universidade Federal de Uberlândia, Uberlândia, MG. [2]. Faculdade de Matemática, Universidade Federal de Uberlândia, Uberlândia, MG.

\begin{abstract}
Introduction: Antimicrobial resistance is an increasing threat in hospitalized patients, and inappropriate empirical antimicrobial therapy is known to adversely affect outcomes in ventilator-associated pneumonia (VAP). The aim of this study was to evaluate antimicrobial usage, incidence, etiology, and antimicrobial resistance trends for prominent nosocomial pathogens causing ventilatorassociated pneumonia in a clinical-surgical intensive care unit (ICU). Methods: Gram-negative bacilli and Staphylococcus aureus causing VAP, as well as their antimicrobial resistance patterns and data on consumption (defined daily dose [DDD] per 1,000 patient days) of glycopeptides, extended-spectrum cephalosporins, and carbapenems in the unit were evaluated in two different periods (A and B). Results: Antimicrobial use was high, mainly of broad-spectrum cephalosporins, with a significant increase in the consumption of glycopeptides $(\mathrm{p}<0.0001)$ and carbapenems $(\mathrm{p}<0.007)$ in period B. For Acinetobacter baumannii and members of the Enterobacteriaceae family, 5.27- and 3.06-fold increases in VAPs, respectively, were noted, and a significant increase in resistance rates was found for imipenem-resistant $A$. baumannii $(\mathrm{p}=0.003)$ and third-generation cephalosporinsresistant Enterobacteriaceae $(p=0.01)$ isolates in this same period. Conclusions: Our results suggest that there is a link between antibiotics usage at institutional levels and resistant bacteria. The use of carbapenems was related to the high rate of resistance in A. baumannii and therefore a high consumption of imipenem/meropenem could play a major role in selective pressure exerted by antibiotics in A. baumannii strains.
\end{abstract}

Keywords: Antibiotic consumption. Intensive care unit. Ventilator-associated pneumonia. Antimicrobial resistance.

\section{INTRODUCTION}

Ventilator-associated pneumonia (VAP) is the most-frequent intensive care unit (ICU)-acquired infection, occurring in 9.0$24 \%$ of patients intubated for longer than $48 \mathrm{~h}$. It is associated with increased morbidity, prolonged hospitalization, and increased healthcare costs ${ }^{1}$.

Antimicrobial resistance is an increasing threat in hospitalized patients, and both mortality and morbidity from infection are greater when caused by antimicrobial-resistant bacteria ${ }^{2,3}$. Among these resistant bacteria, extended-spectrum cephalosporinresistant Enterobacteriaceae, carbapenem-resistant $P$ seudomonas aeruginosa and Acinetobacter baumannii, and ciprofloxacinresistant Enterobacteriaceae and non-fermentative Gram-negative bacilli (NFGNB) are of great concern because antimicrobial therapy for infections due to these resistant pathogens remains a clinical dilemma ${ }^{2,4}$. Increases in the prevalence of these

Address to: Dr. Michel Rodrigues Moreira. Lab. Microbiologia/ICBIM/UFU. Av. Pará 1720, Bloco 4C/36, Campus Umuarama, 38400-902 Uberlândia, MG, Brasil.

Phone/Fax: 5534 3218-2236

e-mail: moreira.mr@hotmail.com

Received in 21/06/2012

Accepted in 21/11/2012 resistant pathogens are frequently related to the high selective pressure of antimicrobials commonly used in hospitalized patients, particularly extended-spectrum cephalosporins, $\beta$-lactam $+\beta$-lactamase inhibitor combinations, carbapenems, fluoroquinolones, and aminoglycosides ${ }^{2,5}$.

Inappropriate empirical antimicrobial therapy is known to adversely affect outcome in pneumonia associated with a mechanical ventilator ${ }^{6}$ and needs to be tailored to the institution's microbial ecology and the length of time the patient was in the hospital before pneumonia developed ${ }^{4}$. This question is frequent in Brazilian ICUs ${ }^{7}$. Multidrug-resistant organisms are far higher in ICUs in Latin America, Asia, Africa, and Europe than in U.S. ICUs ${ }^{8}$.

This report aims to evaluate antimicrobial usage, incidence, etiology, and antimicrobial resistance trends for prominent nosocomial pathogens causing ventilator-associated pneumonia in a clinical-surgical ICU in a Brazilian university hospital.

\section{METHODS}

\section{Hospital and study design}

This work was performed at the Uberlândia Federal University Hospital Clinic (HC-UFU) which is a teaching hospital with 500 beds and a clinical-surgical ICU of adults with 15 beds. 
We conducted a cross-sectional study where the incidence density of major Gram-negative bacteria and Staphylococcus aureus causing VAP were expressed as the number of isolates per 1,000 patients-day (pd) per month in two different periods: A (May 2006 to April 2007) and B (September 2008 to August 2010). Only the first episode of VAP was considered for each patient. Endotracheal aspirate was collected by probe number 12 early in the morning by health professionals (physiotherapists and nurses) in charge of the procedure and transported in a sterile tube to the Microbiology Laboratory. Isolates were identified by conventional biochemical tests.

\section{Definition of hospital ventilator-associated pneumonia}

The patients were under a mechanical ventilator for a period $\geq 48 \mathrm{~h}$ after being admitted to the ICU, with new and/or progressive radiological infiltrate, and at least under two of the following criteria: purulent sputum, temperature higher than $38.5^{\circ} \mathrm{C}$ or lower than $35^{\circ} \mathrm{C}$, and leukocyte count higher than $10,000 / \mu \mathrm{L}$ with deviation to the left or lower than $3,000 / \mu \mathrm{L}$; and positive quantitative culture of the endotracheal aspirate [count $\geq 10^{6}$ colony-forming units $\left./ \mathrm{ml}(\mathrm{CFU} / \mathrm{ml})\right]^{9}$.

\section{Antibiotic consumption}

Data on antibiotic consumption were evaluated in period A and May 2009 to August 2010 and were expressed as the number of defined daily doses (DDDs)/1,000 patients-day (pd) for the main classes of antibiotics used in our ICU: glycopeptides (vancomycin and teicoplanin), carbapenems (imipenem, meropenem, and ertapenem), and extendedspectrum cephalosporins (ceftriaxone and cefepime).

There were no interventions or changes in the antimicrobial use policy in the institution between the two periods.

\section{Trends in resistance}

To determine the trend of resistance in major Gram-negative pathogens and $S$. aureus causing VAPs in ICU patients in the HC-UFU, data on the disk diffusion susceptibilities of these organisms were interpreted according to Clinical and Laboratory Standards Institute (CLSI) criteria ${ }^{10}$, by the diameter of inhibition halo formed, using the following antimicrobial discs (Oxoid LTD., England): oxacillin (1ug), penicillin (10mg), erythromycin (15mg), cefoxitin (30mg), clindamycin (2mg), rifampicin (5mg), chloramphenicol $(30 \mathrm{mg})$, vancomycin $(30 \mathrm{mg})$, ciprofloxacin $(5 \mathrm{mg})$, gentamicin $(10 \mathrm{mg})$, cefepime $(30 \mathrm{mg})$, tetracycline $(30 \mathrm{mg})$ and sulphazotrim (25mg) for Gram-positive; imipenem (10mg), ciprofloxacin (5mg), ceftriaxone $(30 \mathrm{mg})$, gentamicin $(10 \mathrm{mg})$, piperacillin-tazobactam (100/10mg), polymyxin B (300u), cefepime (30mg), aztreonan (30mg), sulphazotrim $(25 \mathrm{mg})$ and tetracycline $(30 \mathrm{mg})$ for Gram-negative.

\section{Statistical analysis}

Analysis was performed by the Mann-Whitney test or Student $\mathrm{T}$ test after checking normality (Shapiro-Wilk and Lilliefors) and independence of the variables for comparisons between periods $\mathrm{A}$ and $\mathrm{B}$.

Pearson's correlation coefficient was used to determine the relationship between antibiotic consumption and trends in resistance.

The results were considered statistically significant at a level of $5 \%$. The epidemiological data were analyzed through the program Bioestat 5.0 $0^{11}$.

\section{Ethical considerations}

The Ethics Committee for Human Research of the Uberlândia Federal University (UFU) approved the project under number 364/08.

\section{RESULTS}

\section{Etiology of ventilator-associated pneumonias}

Periods A and B incidence density of major Gram-negative bacilli and $S$. aureus causing VAPs are shown in Table 1 and Figures 1 and 2. For A. baumannii and members of the Enterobacteriaceae family, 5.27- and 3.06-fold increases in VAPs were nocted, respectively. On the other hand, there was a 2.0 -fold decrease in the incidence density of $S$. aureus causing VAPs. Among the Gram-negative bacilli isolates, trends of increase in incidence density were significant $(\mathrm{p} \leq 0.05)$ just among A. baumannii and members of the Enterobacteriaceae family causing VAPs (Table 1). Other non-fermenters, except $P$. aeruginosa and $A$. baumannii, were observed only in period $\mathrm{B}$ (1.62 isolates/1,000 patient-days).

TABLE 1 - Incidence density of microorganisms isolates from ventilator-associated pneumonia (isolates/1,000 patient-days) in two different periods in the adult ICU at UFU-HC.

\begin{tabular}{|c|c|c|c|}
\hline Pathogen & $\begin{array}{c}\text { Period A } \\
\text { mean (SD) median }\end{array}$ & $\begin{array}{c}\text { Period B } \\
\text { mean (SD) median }\end{array}$ & $\mathrm{p}^{*}$ \\
\hline Staphylococcus aureus & $4.23(4.27) 3.16$ & $2.11(1.98) 2.15$ & 0.21 \\
\hline OSSA & $1.82(1.80) 2.15$ & $1.74(2.04) 2.15$ & 0.80 \\
\hline Pseudomonas aeruginosa & $4.36(3.90) 2.30$ & $5.02(3.45) 4.30$ & 0.43 \\
\hline imipenem-resistant & $0.18(0.62) 0.0$ & $3.12(3.41) 2.15$ & 0.003 \\
\hline Enterobacteriaceae & 0.90 (1.94) 0.0 & $2.75(2.45) 2.15$ & 0.02 \\
\hline resistant to third- generation cephalosporins & $0.18(0.62) 0.0$ & $1.54(1.63) 2.15$ & 0.01 \\
\hline
\end{tabular}

ICU: intensive care unit; UFU-HC: Uberlândia Federal University-Hospital Clinic; SD: standard deviation; ORSA: oxacillin-resistant Staphylococcus aureus; OSSA: oxacillin-sensitive Staphylococcus aureus. *Mann-Whitney test. 


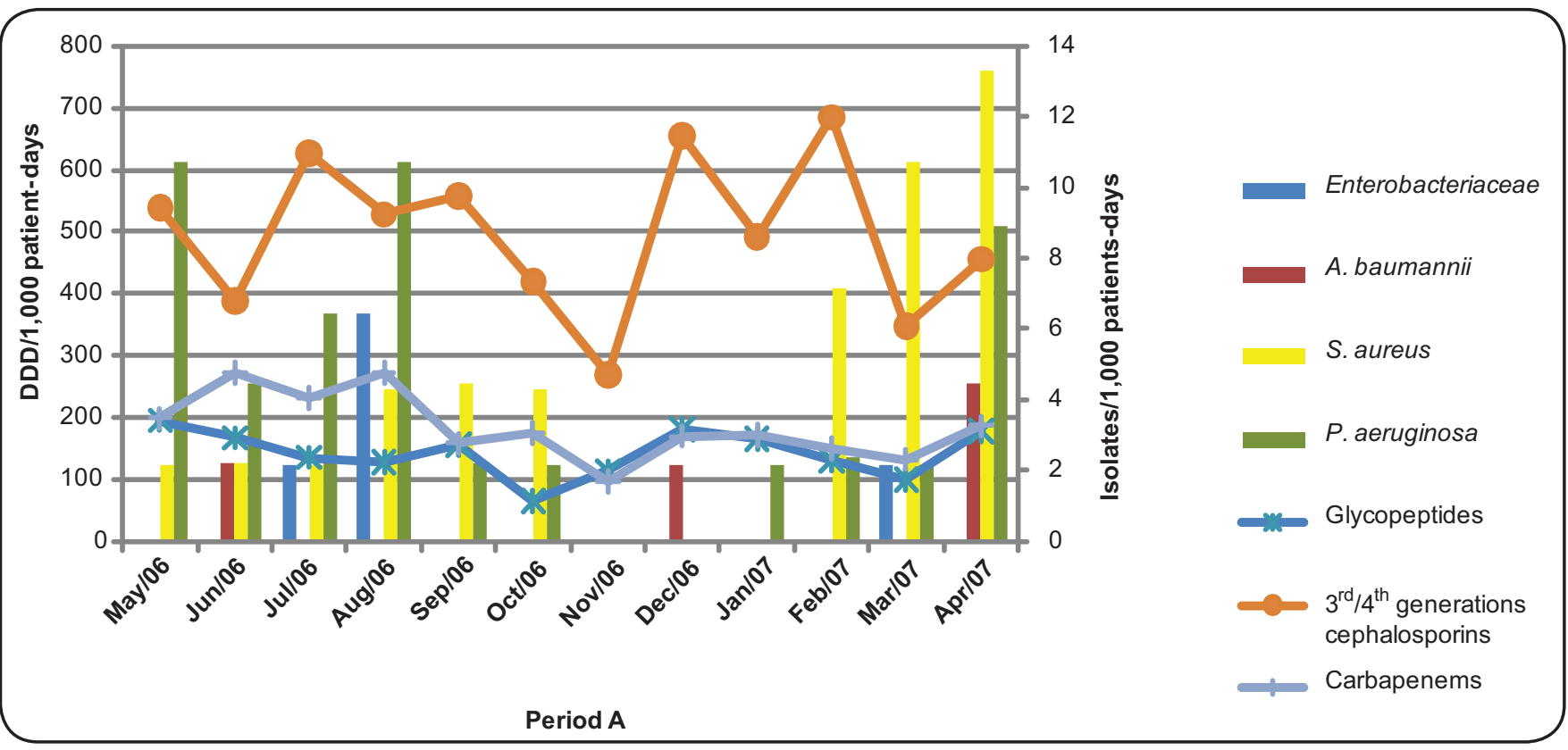

FIGURE 1 - Relationship between incidence density of microorganisms isolated from ventilator-associated pneumonia (isolates/1,000 patient-days) and density of use of antimicrobials in defined daily doses (DDD/1,000 patient-days) in the adult ICU at UFU-HC for period A.

DDD: defined Daily Doses; ICU: intensive care unit; UFU-HC: Uberlândia Federal University-Hospital Clinic; A. baumannii: Acinetobacter baumannii; S. aureus: Staphylococcus aureus; P. aeruginosa: Pseudomonas aeruginosa.

\section{Period antibiotic consumption}

Table 2 shows the consumption of three classes of antibiotics in both periods. There was no significant variation in the consumption of broad-spectrum cephalosporins as opposed to glycopeptides (1.88fold) and carbapenems (1.43-fold) when comparing periods A and B (Table 2, Figures 1 and 2).

In period $\mathrm{A}$, the density of use of third- or fourth-generation cephalosporins grew in respect to glycopeptides and carbapenems (Table 2). In period $\mathrm{B}$, the consumption of antimicrobials was higher than in period A for all classes evaluated, with emphasis on higher-density use of broad-spectrum cephalosporins (Table 2).

\section{Relationship between antibiotic consumption and resistance}

The overall rates of resistance to imipenem were $25 \%$ and $80.9 \%$ in A. baumannii and $62.5 \%$ and $45.5 \%$ in P. aeruginosa in periods A and B, respectively. For S. aureus, overall rates of resistance to oxacillin were $56.5 \%$ and $17.4 \%$ in periods $A$ and $B$, respectively. Regarding third-generation cephalosporins, the overall rates of resistance were $20 \%$ and $56.7 \%$ in Enterobacteriaceae isolates in periods A and B, respectively. Table 1 shows the trends of resistance among Gram-negative pathogens and S. aureus.

In period $\mathrm{A}$, only the consumption of carbapenems showed a significant correlation (Pearson $\mathrm{r}=0.66 / \mathrm{p}=0.02$ ) with the occurrence of VAPs by P. aeruginosa, especially with strains resistant to imipenem (Pearson $r=0.70 / p=0.01$ ) (Figure 3). The rates of antibiotic resistance of other organisms were not correlated with the consumption of antimicrobials evaluated in the Pearson correlation test.

A significant increase in resistance rates in period $B$ was found for imipenem-resistant $A$. baumannii and third-generation cephalosporinsresistant Enterobacteriaceae isolates. This same period showed a significant increase in consumption of carbapenems, and the use of broad-spectrum cephalosporins was still higher than during period $\mathrm{A}$, but there was no correlation with resistance rates of these microorganisms in the Pearson correlation test.

Figures 1 and $\mathbf{2}$ show the relationship between consumption of antibiotics and the etiology of VAPs.

TABLE 2 - Average consumption of antibiotics in DDDs per 1,000 patient-days of glycopeptides, carbapenems, and extended-spectrum cephalosporins in adult ICU at UFUHC in two different periods.

\begin{tabular}{lcc}
\hline Antimicrobial & Period A & Period B \\
& mean (SD) median & mean (SD) median \\
\hline Glycopeptides & $142.98(37.93) 145.68$ & $269.56(82.12) 237.02$ \\
Extended-spectrum cephalosporins & $496.87(127.03) 510.36$ & $551.26(156.34) 517.79$ \\
Carbapenems & $184.29(37.93) 179.62$ & 0.0001 \\
\hline
\end{tabular}

DDDs: defined daily doses; ICU: intensive care unit; UFU-HC: Uberlândia Federal University-Hospital Clinic; SD: standard deviation; *Student T test. 


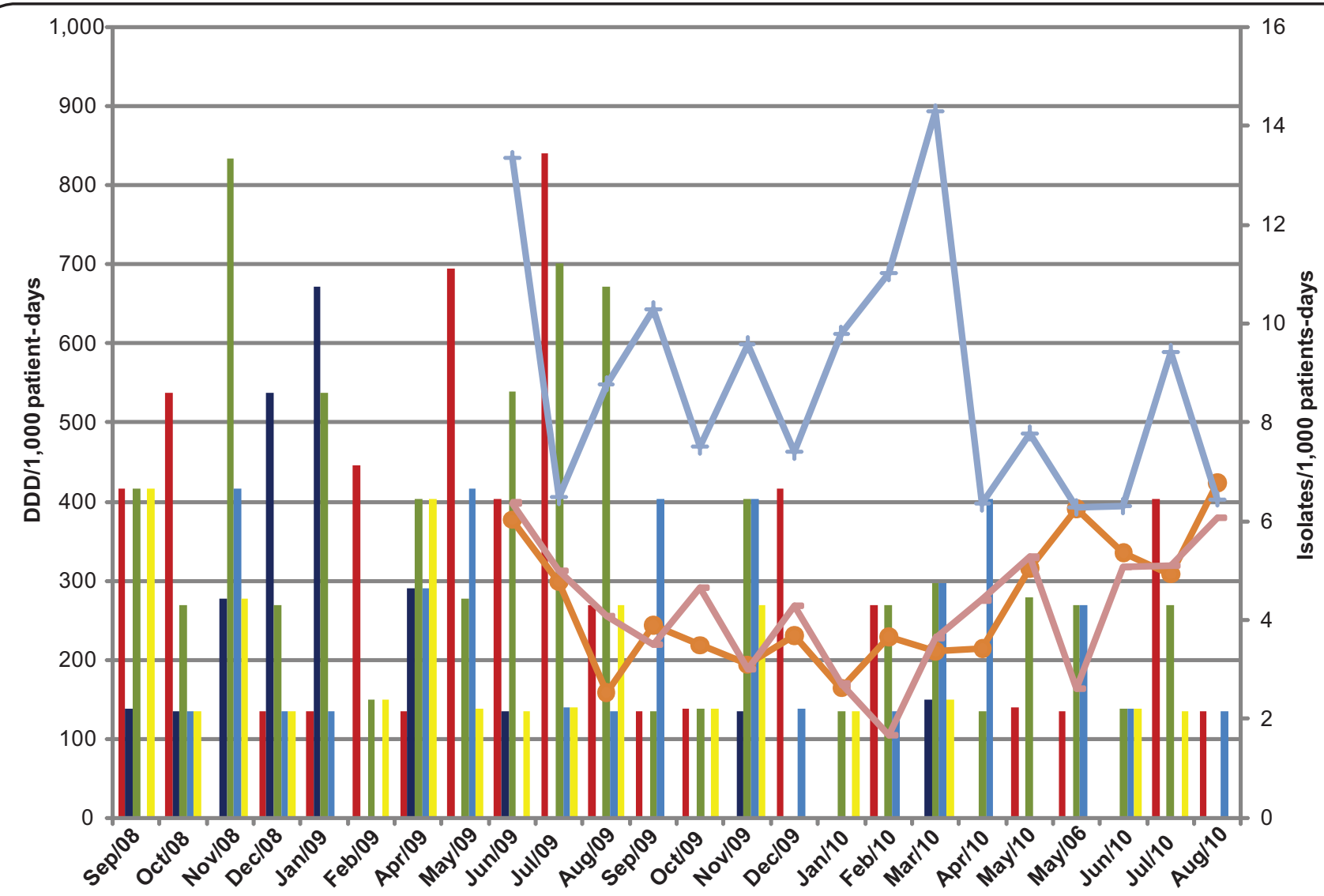

Period B
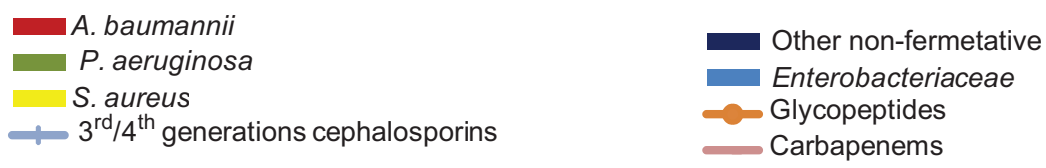

FIGURE 2 - Relationship between incidence density of microorganisms isolated from ventilator-associated pneumonia (isolates/1,000 patient-days) and density of use of antimicrobials in defined daily doses (DDD/1,000 patient-days) in the adult ICU at UFU-HC for period $B$.

DDD: defined daily doses; ICU: intensive care unit; UFU-HC: Uberlândia Federal University-Hospital Clinic; A. baumannii: Acinetobacter baumannii; S. aureus: Staphylococcus aureus; P. aeruginosa: Pseudomonas aeruginosa.

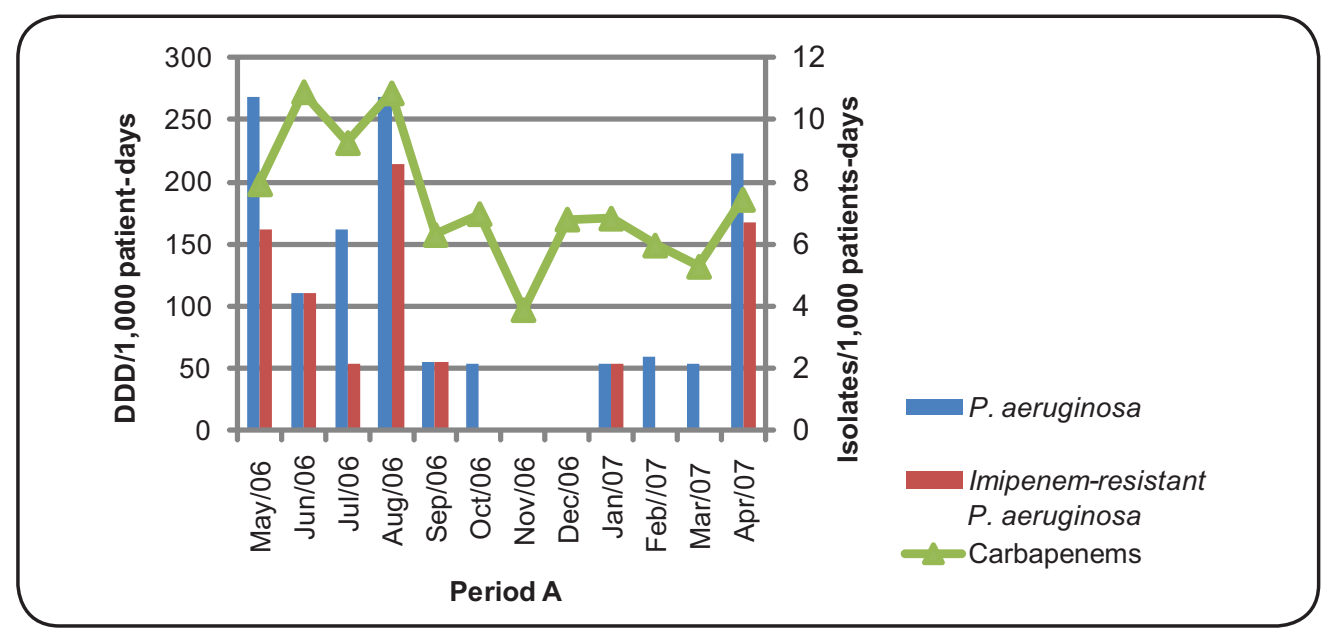

FIGURE 3 - Relationship between incidence density of Pseudomonas aeruginosa isolated from ventilator-associated pneumonia (isolates/1,000 patientdays) susceptible (Pearson $r=0.66 / p=0.02$ ) or resistant (Pearson $r=0.70 / p=0.01$ ) to imipenem and density of use of Carbapenems in defined daily doses (DDD/1,000 patient-days) in the adult ICU at UFU-HC for period $A$.

DDD: defined daily doses; ICU: intensive care unit; UFU-HC: Uberlândia Federal University-Hospital Clinic; A. baumannii: Acinetobacter baumannii; S. aureus: Staphylococcus aureus; P. aeruginosa: Pseudomonas aeruginosa. 


\section{DISCUSSION}

Regarding the etiology of VAPs, we observed a decrease in the frequency in VAPs caused by $S$. aureus and an increase in the frequency of VAPs by Gram-negative bacilli in period B. Changes in the frequency of these pathogens may be due to multiple factors (e.g., implementation of targeted surveillance, multidrug-resistant organism outbreaks, active surveillance, etc.) besides the agents may fluctuate over time ${ }^{12}$. Several studies found that prior administration of antibiotics can alter the distribution of microbial pathogens isolated from patients with VAP. For example, in a prospective study of 129 episodes of VAP, prior use of antibiotics significantly decreased the incidence of VAP caused by Gram-positive cocci or Haemophilus influenzae but increased the rate of those caused by P. aeruginosa ${ }^{13}$. In our ICU, we observed a decrease in rates of oxacillin-resistant Staphylococcus aureus (ORSA) despite the highest use of glycopeptides for empirical antimicrobial treatment of infections in the period $B$ $(\mathrm{p}<0.0001)$. In the UK hospitals, the introduction of mandatory surveillance and the use of a national clean your hands campaign resulted in a $50 \%$ reduction of ORSA bacteraemia ${ }^{14}$. In U.S. hospitals, ORSA central line-associated bloodstream infections (BSI) incidence also declined $50 \%$ or more in recent years in all major adult ICU types, as reported by the Centers for Disease Control and Prevention (CDC) ${ }^{15}$. These observations are consistent with reports of successful prevention efforts by health care teams that implemented programs designed to improve care practices ${ }^{15}$. Such decreases have been evident in other developed countries with national health care-associated infection surveillance and prevention efforts ${ }^{15-17}$.

The incidence of VAP due to major Gram-negative bacteria increased over time, but $P$. aeruginosa remained the most-prevalent bacteria, $40 \%$ and $32.4 \%$ in periods A and B, respectively, as represented in other South American ICUs ${ }^{18}$. In our study, $62.5 \%$ and $45.5 \%$ of $P$. aeruginosa isolates were resistant to imipenem in periods $\mathrm{A}$ and $\mathrm{B}$, respectively. These rates are high when compared with those in other studies ${ }^{8,19}$.

Acinetobacter baumannii is another important cause of nosocomial infections in many hospitals, which is difficult to both control and treat because of its prolonged environmental survival and its ability to develop resistance to multiple antimicrobial agents ${ }^{20,21}$. A. baumannii pneumonia occurs predominantly in selected subjects with various risk factors such as mechanical ventilator, residence in an ICU, and prior antibiotic use mainly of broad-spectrum drugs such as thirdgeneration cephalosporins and carbapenems $\mathrm{s}^{22}$. In our study, A. baumannii rates increased in period $\mathrm{B}(\mathrm{p}=0.008)$, and this bacteria was the second-most-frequently isolated in this period when the use of broad-spectrum cephalosporins and carbapenems were higher than in period $\mathrm{A}(\mathrm{p}=0.33$ and 0.007 , respectively) and extremely high when compared to rates of use in U.S. ${ }^{23}$ (37.8 and 144.1 DDDs/1,000pd for carbapenems and $3^{\text {rd }}$ generation cephalosporins, respectively) and German ${ }^{5}$ ICUs (83.7 and 109.5 DDDs/1,000pd for carbapenems and $3^{\text {rd }}$ generation cephalosporins, respectively). A. baumannii appears to have a propensity for developing antimicrobial resistance extremely rapidly. Moreover, this resistance is multiple, causing serious therapeutic problems ${ }^{20}$. Carbapenems are usually the antibiotics of choice for treating serious infections caused by this microorganism. However, reports of imipenem-resistant A. baumannii strains have been rising steadily during the past few year, and these isolates are often multidrug-resistant ${ }^{20,21,24}$. Although these multiresistant $A$. baumannii strains may still retain susceptibility to polymyxins (i.e., colistin and polymyxin B), sulbactam and possibly tigecycline pan-resistant isolates that are resistant to all available drugs are now reported ${ }^{24}$. In our study, $25 \%$ and $80.9 \%$ of the isolates of $A$. baumannii were resistant to carbapenems in periods $\mathrm{A}$ and $\mathrm{B}$, respectively $(\mathrm{p}=0.003)$.

Gram-negative bacilli of the Enterobacteriaceae family are common causes of health-care-associated pneumonias ${ }^{25}$. Emerging resistance in this microorganism is a significant problem that requires immediate attention, and the increasing prevalence of multidrug-resistance Enterobacteriaceae challenges the use of third-generation cephalosporins for empirical treatment of nosocomial infections ${ }^{25,26}$. In our study, the rates of Enterobacteriaceae isolates increased in period B $(p=0.02)$ and were the third-most-isolated pathogen during this period; $20.0 \%$ and $56.7 \%$ of these microorganisms were resistant to third-generation cephalosporins in periods $\mathrm{A}$ and $\mathrm{B}$, respectively $(\mathrm{p}=0.01)$. The emergence of extendedspectrum $\beta$-lactamases (ESBLs) necessitated the increased use of carbapenems, but this increased use of drugs of last resort may be contributing to the emergence of multidrug-resistant non-fermentative Gram-negative bacillii ${ }^{27,28}$.

The root causes of the rapid emergence and dissemination of drug-resistant bacteria in hospitals are multifactorial ${ }^{2,29,30}$, including mainly the high selective pressure that results from inappropriate and widespread use of antimicrobial agents particularly in ICUs; cross transmission from patient to patient owing to inconsistent application of appropriate infection control measures; clonal spreading of resistant bacteria and horizontal transfer of resistance genes; and a complex relationship between resistance and use of a variety of antimicrobials ${ }^{2,29,31}$. However, increasing resistance may further drive increased consumption of several so-called last-line antimicrobial agents ${ }^{2}$. In this study, the increase in the incidence of VAP due to multidrug-resistant A. baumannii and third-generation cephalosporins-resistant Enterobacteriaceae resulted in an increase of carbapenems. The increased use of these agents was associated with an increase in the incidence of VAPs due to carbapenem-resistant $A$. baumannii.

Our results suggest a link between antibiotics usage at institutional levels and resistant bacteria. The emergence of $P$. aeruginosa in our ICU necessitated the increased use of carbapenems, which may contribute to the emergence of multidrug-resistant non-fermentative Gram-negative bacilli, mainly A. baumannii. Antibiotic resistance is an inevitable consequence of inappropriate antibiotic use, which is more likely in units with high prevalence of multidrug-resistant microorganisms. 


\section{CONFLICT OF INTEREST}

The authors declare that there is no conflict of interest.

\section{FINANCIAL SUPPORT}

Coordenação de Aperfeiçoamento de Pessoal de Nível Superior (CAPES).

\section{REFERENCES}

1. Joseph NM, Sistla S, Dutta TK, Badhe AS, Parija SC. Ventilator-associated pneumonia: role of colonizers and value of routine endotracheal aspirate cultures. Int J Infect Dis 2010; 14:723-729.

2. Hsueh PR, Chen WH, Luh KT. Relationships between antimicrobial use and antimicrobial resistance in Gram-negative bacteria causing nosocomial infections from 1991-2003 at a university hospital in Taiwan. Int J Antimicrob Agents $2005 ; 26: 463-472$.

3. Rhomberg PR, Jones RN, Sader HS, MYSTIC Programme (US) Study Group. Results from the Meropenem Yearly Susceptibility Test Information Collection (MYSTIC)Programme: report of the 2001 data from 15 United States medical centres. Int J Antimicrob Agents 2004; 23:52-59.

4. Peleg AY, Hooper DC. Hospital-Acquired Infections Due to Gram-Negative Bacteria. N Engl J Med 2010; 362:1804-1813.

5. Meyer E, Jonas D, Schwab F, Rueden H, Gastmeier P, Daschener FK. Design of a Surveillance System of Antibiotic Use and Bacterial Resistance in German Intensive Care Units (SARI). Infection 2003; 31:208-215.

6. Waele JJ, Ravyts M, Depuydt P, Blot SI, Decruyenaere J, Vogelaers D. De-escalation after empirical meropenem treatment in the intensive care unit: Fiction or reality? J Crit Care 2010; 25:641-646.

7. Moreira MR, Cardoso RL, Almeida AB, Gontijo Filho PP. Risk Factor and Evolution of Ventilator-Associated Pneumonia by Staphylococcus aureus Sensitive or Resistant to Oxacillin in Patients at the Intensive Care Unit of a Brazilian University Hospital. Braz J Infect Dis 2008; 12:499-503.

8. Rosenthal VD, Maki DG, Jamulitrat S, Medeiros EA, Todi SK, Gomez DY, et al. International Nosocomial Infection Control Consortium (INICC) report, data summary for 2003-2008, issued June 2009. Am J Infect Control 2010; 38:95-106.

9. Alp E, Voss A. Ventilator Associated Pneumonia and Infection Control. Ann Clinic Microbiol Antimicrob 2006; 5:7.

10. Clinical and Laboratory Standards Institute (CLSI). Performance Standards for Antimicrobial Susceptibility Testing. Twentieth Informational Supplement. CLSI Document M100-S20 2010; 29:1-165.

11. BioEstat Software. BioEstat version 5.0. [Acessed 2011 May 3]. Available from http://www.mamiraua.org.br/download.

12. Chuang YC, Chen YC, Chang SC, Sun CC, Chang YY, Chen ML, et al. Secular trends of healthcare-associated infections at a teaching hospital in Taiwan, 1981-2007. J Hosp Infect 2010; 76:143-149.

13. Parker CM, Kutsogiannis J, Muscedere J, Cook D, Dodek P, Day AG, et al. Ventilator-associated pneumonia caused by multidrug-resistant organisms or Pseudomonas aeruginosa: Prevalence, incidence, risk factors and outcomes. J Crit Care 2008; 23:18-26.

14. Pearson A. Historical and changing epidemiology of healthcare-associated infections. J Hosp Infect 2009; 73:296-304.
15. Burton DC, Edwards JR, Horan TC, Jernigan JA, Fridkin SK. Methicillin-Resistant Staphylococcus aureus Central Line-Associated Bloodstream Infections in US Intensive Care Units, 1997-2007. JAMA 2009; 301:727-736.

16. United Kingdom Health Protection Agency Surveillance of Healthcare Associated Infections Report 2007. London, England: Healthcare Associated Infection \& Antimicrobial Resistance Department, UK Health Protection. [Cited 2008 July 31]. Available from: http://www.hpa.org.uk/web/HPAwebFile/ HPAweb_C/1196942169446.

17. Meyer E, Schwab F, Gastmeier P, Jonas D, Rueden H, Daschner FD. Methicillinresistant Staphylococcus aureus in German intensive care unit during 2000-2003: data from project SARI (Surveillance of Antimicrobial Use and Antimicrobial Resistance in Intensive Care Units). Infect Control Hosp Epidemiol 2006; 27:146-154

18. Vincent J, Rello J, Marshall J, Silva E, Anzueto A, Martin CD, et al. International Study of the Prevalence and Outcome of Infection in Intensive Care Units. JAMA 2009; 302:2323-2329.

19. Andrade SS, Sader HS, Barth AL, Ribeiro J, Zoccoli C, Pignatari AC, et al Antimicrobial Susceptibility of Gram-Negative Bacilli Isolated in Brazillian Hospitals Participating in the SENTRY Program (2003-2008). Braz J Infect Dis 2008; 12 (suppl II):3-9.

20. Baran G, Erbay A, Bodur H, Öngürü P, Akinci E, Balaban N, et al. Risk factors for nosocomial imipenem-resistant Acinetobacter baumannii infections. Int J Infect Dis 2008; 12:16-21.

21. Neonakis IK, Spandidos DA, Petinaki E. Confronting multidrug-resistant Acinetobacter baumannii: a review. Int J Antimicrob Agents 2011; 37: 102-109.

22. Ferrara AM. Potentially multidrug-resistant non-fermentative Gram-negative pathogens causing nosocomial pneumonia. Int J Antimicrob Agents 2006; 27: 183-195.

23. National Nosocomial Infections Surveillance (NNIS) System Report, data summary from January 1992 through June 2004, issued October 2004. Am J Infect Control 2004; 32:470-485.

24. Giske CG, Monnet DL, Cars Otto, Carmeli Y. Clinical and Economic Impact of Common Multidrug-Resistant Gram-Negative Bacilli. Antimicrob Agents Chemother 2008; 52:813-821.

25. Paterson DL. Resistance in gram-negative bacteria: Enterobacteriaceae. Am J Infect Control 2006; 34:S20-S28.

26. Aubron C, Chaari A, Bronchard R, Armand-Lefèvre L, Montravers P, Régnier B, et al. High level cephalosporin-resistant Enterobacteriaceae ventilator-associated pneumonia: prognostic factors based on a cohort study. J Hosp Infection 2011; 77:64-69.

27. Isturiz R. Global resistance trends and the potential impact on empirical therapy. Int J Antimicrob Agents 2008; 32 (suppl IV):201-206.

28. Abreu AG, Marques SG, Monteiro-Neto V, Carvalho RML, Gonçalves AG. Noscomial infection and characterization of extended-spectrum $\beta$-lactamasesproducing Enterobacteriaceae in Northeast Brazil. Rev Soc Bras Med Trop 2011; 44:441-446.

29. White RL, Friedrich LV, Mihm LB, Bosso JA. Assessment of the relationship between antimicrobial usage and susceptibility: differences between the hospital and specific patient-care areas. Clin Infect Dis 2000; 31:16-23.

30. Neves MT, Lorenzo MEP, Almeida RAMB, Fortaleza CMCB. Antimicrobial use and incidence of multidrug-resistance Pseudomonas aeruginosa in a teaching hospital: an ecological approach. Rev Soc Bras Med Trop 2010; 43:629-632.

31. Warren DK, Fraser VJ. Infection control measures to limit antimicrobial resistance. Crit Care Med 2001; 29 (suppl IV): 128-134. 